Arq. Bras. Med. Vet. Zootec., v.66, n.2, p.579-582, 2014

\title{
Anatomopatologia de bursite cervical (oncocercose) encontrada em bovinos abatidos sob inspeção estadual no estado do Rio de Janeiro
}

\author{
[Anatomopathology of onchocerciases (cervical bursitis) in slaughtered bovine \\ in the north of Rio de Janeiro state] \\ A.S.O. Santos ${ }^{1}$, R.S. Costa ${ }^{2}$, R.F.R. Costa ${ }^{3}$, L.S. Lemos $^{1}$, E.C.Q. Carvalho ${ }^{1}$ \\ ${ }^{1}$ Universidade Estadual do Norte Fluminense Darcy Ribeiro - UENF - Campos dos Goytacazes, RJ \\ ${ }^{2}$ Serviço de Inspeção Estadual - Rio de Janeiro, RJ \\ ${ }^{3}$ Defesa Agropecuária do Rio de Janeiro - Niterói, RJ
}

\begin{abstract}
RESUMO
A patologia descritiva das lesões em animais domésticos de açougue permite enriquecer a literatura médica veterinária especializada em inspeção sanitária de carnes, assim como subsidiar tecnicamente os profissionais inspetores. A oncocercose é uma parasitose causada pelo nematódeo Onchocerca sp, sendo que a espécie O. gutturosa é a que mais acomete bovinos na América do Sul. Foram avaliados, pelo exame anatomopatológico, dois casos de lesões localizadas no ligamento nucal de bovinos abatidos para o consumo. A macroscopia de um caso revelou bursite crônica, representada por grande quantidade de líquido citrino e viscoso e, ainda, muitos corpúsculos livres, elípticos e achatados desprovidos de raiz (arrizo). A microscopia dessas estruturas evidenciou moldes de fibrinas amorfos e eosinofílicos. O segundo caso foi caracterizado por bursite aguda, e a microscopia das lesões ligamentar e periligamentar revelou granulomas epitelioides com reação gigantocitária, centralizados por formações semelhantes ao Onchocerca sp.
\end{abstract}

Palavras-chave: bovino, Onchocerca sp., parasitose, histopatologia

\begin{abstract}
The descriptive pathology of lesions in butcher's domestic animals contribute to enrich literature specialized in veterinary sanitary inspection of meat as well as to guide professional meat inspectors. Oncorcecose is a parasitic disease caused by the nematode Onchocerca $s p$, and the O. gutturosa species affects cattle in South America. Two cases of lesions located in the nuchal ligament of cattle slaughtered for consumption were evaluated by pathological examination. Macroscopic analysis revealed a case of chronic bursitis represented by a large amount of clear and viscous liquid, and also many free, elliptical and flat corpuscles. Microscopy showed arrizoides molds fibrin, amorphous, and eosinophilic structures. The second case was characterized by acute bursitis and microscopic lesions and ligament periligamentous revealed multiple epithelioid granulomas and giant cells centered on formations similar to Onchocerca $s p$.
\end{abstract}

Keywords: bovine, Onchocerca sp, parasitosis, histopathology

\section{INTRODUÇÃO}

Os nematódeos do gênero Onchocerca, responsáveis por causar a parasitose oncocercose, são longos e finos. Quando adultos, medem até $80 \mathrm{~cm}$, e as microfilárias variam de 200 a $260 \mathrm{~mm}$. Caracterizam-se pela cauda curta,

Recebido em 20 de março de 2012

Aceito em 30 de setembro de 2013

E-mail: alesi_vet@hotmail.com agudamente pontuda, e pela ausência de bainha (Foreyt, 2005). O ciclo biológico é heteroxeno, e os vetores são dípteros. Este ciclo é muito semelhante ao dos filarídeos, diferindo no fato de as microfilárias serem inoculadas pelo vetor nos espaços tissulares da pele e não na circulação sanguínea. Nem as microfilárias nem os adultos promovem qualquer 
alteração patológica significativa. Entretanto, os nematódeos adultos podem acarretar a formação de granulomas, quando nas regiões periligamentares (bainha/tenovaginites) e na bolsa atlantal (arco dorsal do atlas) e/ou na bolsa supraespinhal situada na segunda vértebra torácica (Jones et al., 2000). Estes granulomas são epitelioides, gigantocitários e centralizados pelo parasita. Algumas vezes, são caseosos e calcificados. Podem abrir as portas para outros agentes, como: Actinomyces spp., Streptococcus spp., Pseudomonas spp., Pasteurella spp., entre vários outros, complicando com a bursite (Freitas, 1999).

A oncocercose é de ocorrência mundial. No Brasil, a espécie Onchocerca gutturosa foi à única descrita em bovinos (Silva, 1982). Esta se localiza, com maior frequência, no tecido conjuntivo adjacente ao ligamento nucal ou na fáscia adjacente aos principais ossos dos membros. O presente trabalho teve o objetivo de relatar, descrever e discutir a anatomopatologia de dois casos de oncocercose bovina (bursite cervical), em razão da escassez do assunto na literatura especializada nacional.

\section{CASUÍSTICA}

$\mathrm{Na}$ inspeção sanitária estadual de bovinos de abate provenientes de matadouros-frigoríficos localizados no norte fluminense, na linha I - inspeção das faces externa e interna da parte cranial das meias-carcaças e linfonodos pré-escapulares - (BRASIL, 1971), foram observados dois casos de bovinos com lesões no ligamento nucal. No caso 1, havia espessamento e pregueamento da parede bursal contendo exsudato seroso e numerosas formações lentiforme, elípticas, de coloração cinzentoesbranquiçada e consistência moderada. No caso 2 , a lesão na bolsa atlantal estava representada por nódulos de aspecto purulento e alguns grânulos irregulares e amarelados, não tendo caráter infiltrativo. As peças foram encaminhadas para o Setor de Morfologia e Anatomia Patológica da UENF para o diagnóstico histopatológico. Amostras das lesões foram fixadas em formol tamponado neutro a $10 \%$, processadas em parafina e coradas pela hematoxilina e eosina (HE).

\section{DISCUSSÃO}

As lesões macroscópicas no caso 1 foram compatíveis com bursite crônica, considerandose que "bursite" é conceituada como inflamação aguda ou crônica de uma bolsa serosa ou sinovial (Aiello, 2001). Consoante os achados do presente trabalho, Daniels e Ladds (1973) descreveram a bursite crônica em bovinos como representada pela grande quantidade de líquido claro e viscoso, contendo corpúsculos livres, regularmente elípticos e achatados. Em lesões mais antigas, é possível ocorrer calcificação dos corpúsculos (Brasileiro Filho et al., 1994). O exame microscópico das formações "arrizo" revelou moldes de fibrinas, amorfos, levemente eosinofílicos, às vezes, com restos celulares. Langenegger et al. (1975) estudaram 17 casos de bursite cervical, sendo que, em quatro, foram descritas inúmeras estruturas "arrizo", lenticulares ou ovoides e com caracterização histológica de massas fibrinosas, amorfas e eosinofílicas. No caso 2, os achados macroscópicos permitiram caracterizar uma bursite aguda. Esta pode ser de natureza exsudativa serosa, serofribrinosa ou purulenta pela invasão de germes piogênicos. Um caso de bursite aguda relatado por Freitas (1999) apresentou lesões inflamatórias com aumento do volume da bolsa, espessamento da parede, exsudação de fibrina e posterior formação de tecidos de granulação. A microscopia, neste caso, revelou que as amostras de lesão ligamentar e periligamentar eram granulomatosas, epitelioides e gigantocitárias múltiplas e que centralizavam formações sugestivas de nematoides Onchocerca sp. (Fig. 1). Nos achados microscópicos relatados por Silva (1982), havia nematoides do gênero Onchocerca, reação granulomatosa com infiltrado linfoplasmocitário, células epitelioides, gigantocitárias e eosinófilos, associados a material hialino, necrótico e fibroso, além de focos de calcificação distrófica e reação fibrovascular (Fig. 2), achados semelhantes aos relatados neste trabalho. A patologia, por não ter caráter zoonótico e por se apresentar contida e organizada, requer um procedimento de toalete seguido do aproveitamento condicional da carcaça. 


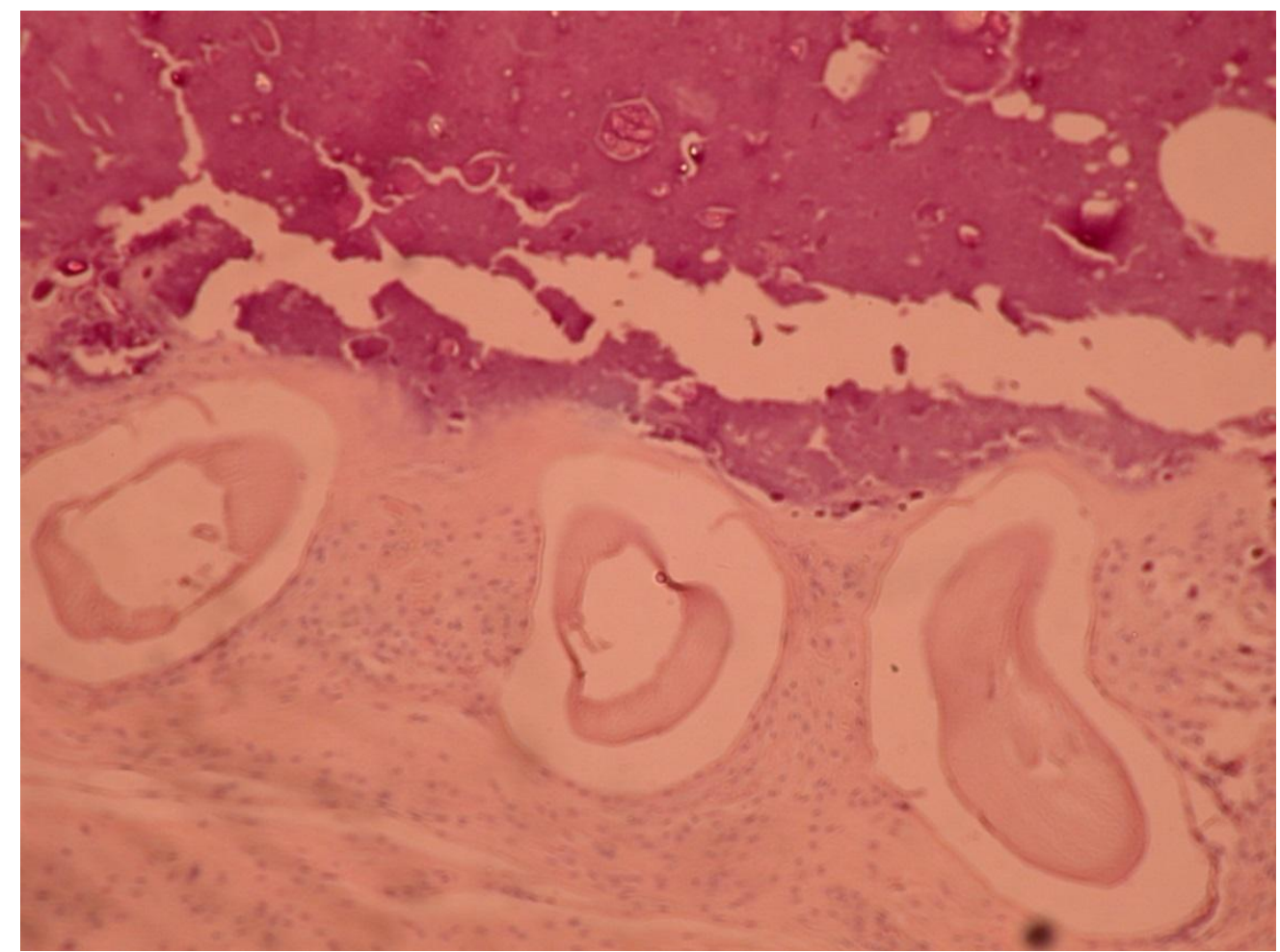

Figura 1. Granulomas epitelioides que centralizavam formações semelhantes a nematoides Onchocerca sp. HE, Obj. 40X.

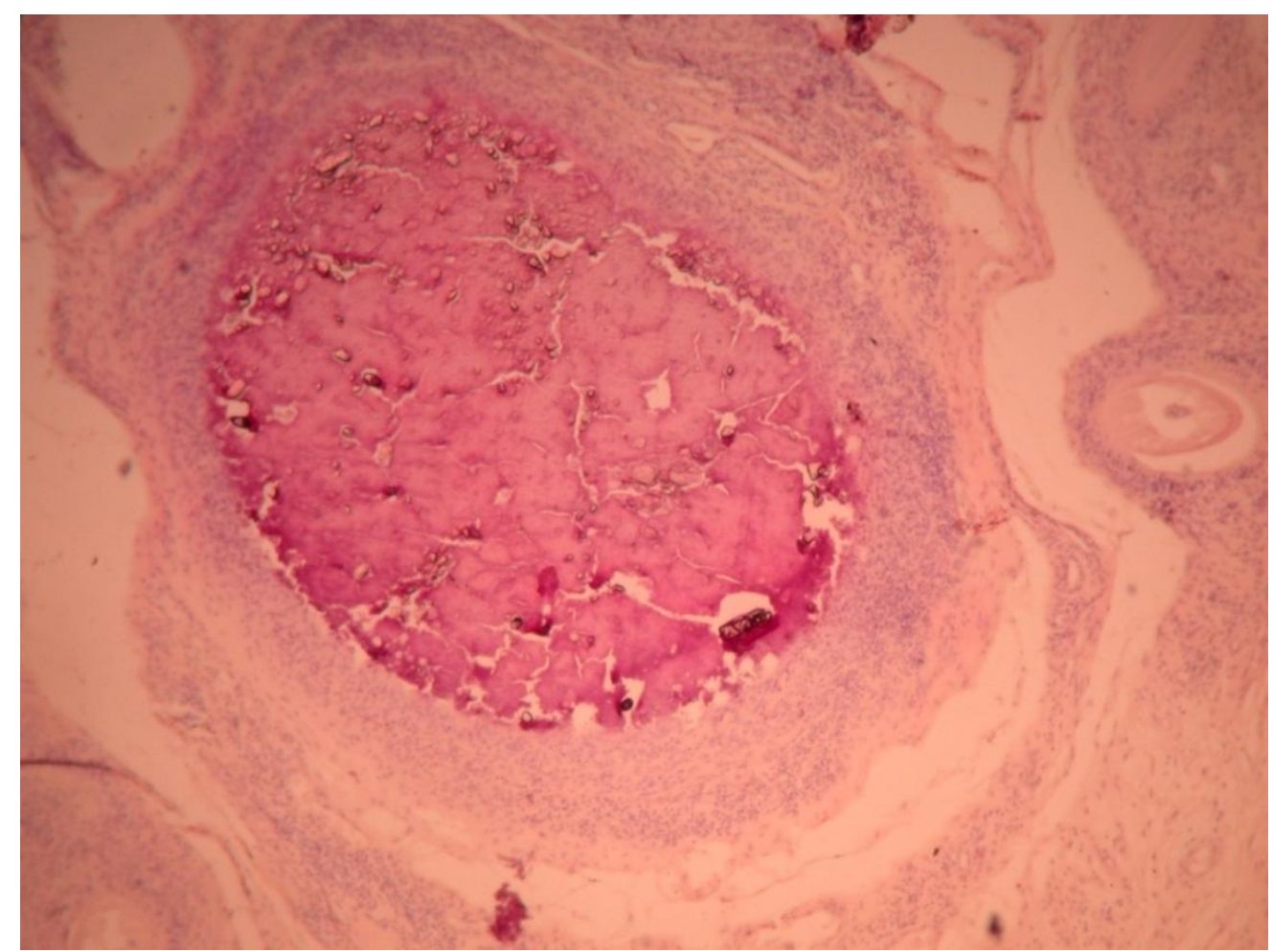

Figura 2. Granuloma evidenciando área de mineralização e necrose caseosa com infiltrado inflamatório de células epitelioides. HE, Obj. 40X. 


\section{CONCLUSÕES}

No Brasil, há poucos estudos sobre bursites em animais domésticos, o que torna oportuna e interessante a patologia descritiva desses dois casos de oncocercose. O diagnóstico histopatológico definitivo de bursite crônica e aguda serviu como ferramenta de apoio aos inspetores de carnes para o correto destino das carcaças.

\section{REFERÊNCIAS}

BRASIL. Padronização de Técnicas, Instalações e Equipamentos para o Abate de Bovinos (normas de bovino). Brasília: Ministério da Agricultura, Pecuária e Abastecimento, 1971.

BRASILEIRO FILHO, G.; PITELLA, J.E.H.; PEREIRA, F.E.L. et al. Bogliolo Patologia. Rio de Janeiro: Guanabara Koogan, 1994. 1243p.

DANIELS, P.W.; LADDS, P.W. "Melon seeds" bodies in bovine supraspinosus bursitis. Aust.Vet. J, v. 49, p.50, 1973.
FOREYT, W.J. Parasitologia Veterinária: Manual de Referência. São Paulo: Roca, 2005. 798p.

FREITAS, M.R. Caracterização anatomopatológica de bursites cervicais de bovinos abatidos em estabelecimentos sob Inspeção Federal no Estado de Goiás. 1999. 65f. Dissertação (Mestrado em Ciência Animal). Escola de Veterinária. Universidade Federal de Goiás.

JONES, T.C.; HUNT, R.D.; KING, N.W. Patologia Veterinária. São Paulo: Manole, 2000. 1392p.

LANGENEGGER, J.; SECCHIN, H.; BAPTISTA, A.M. Bursites brucélicas na cernelha de bovinos de abate e cuidados sanitários no matadouro. Pesq. Agropec. Bras., Ser. Vet., v.10, p.45-49, 1975.

SILVA, D.A.S. Oncocercose bovina no Brasil. Achados anatomopatológicos de interesse em inspeção sanitária de carnes. 1982. 42f. Dissertação (Mestrado em Higiene Veterinária). Faculdade de Veterinária. Universidade Federal Fluminense, Niterói. 